\title{
Physical quality changes of pre-cooked shrimps during frozen storage
}

\author{
Xiejun SUNª, Qianqian JIN ${ }^{\mathrm{b}}$, Xiuxia LIc \\ College of Food Science and Engineering, Bohai University Jinzhou, Liaoning, 121013, China \\ asxjun1@126.com, b727582548@qq.com, clixiuxiaxxx@163.com
}

Keywords: Pre-cooked Chinese shrimp Fenneropenaeus chinensis, frozen storage, physical quality; water distribution and mobility; low-field NMR

\begin{abstract}
The physical quality (texture and color), moisture content, water holding capacity, low-field nuclear magnetic resonance (NMR) transverse relaxation $\mathrm{T}_{2}$ data and the correlation among these indexes in pre-cooked (boiled for $5 \mathrm{~min}$ ) Chinese shrimp Fenneropenaeus chinensis during frozen storage were investigated. The moisture content, water holding capacity, and springiness decreased with the storage time increasing, while $\mathrm{L}^{*}, \mathrm{a}^{*}, \mathrm{~b}^{*}$ and hardness increased. The correlation analysis result showed that the hardness, $\mathrm{L}^{*}, \mathrm{a}^{*}$ and $\mathrm{b}^{*}$ value were direct proportion to $\mathrm{P}_{2 \mathrm{~b}}$, the springiness was direct proportion to $\mathrm{P}_{21}$ and $\mathrm{P}_{22}$, respectively, moisture content was inverse proportion to hardness, while direct proportion to springiness. The changes of water mobility and distribution of pre-cooked Chinese shrimp Fenneropenaeus chinensis resulted in the changes of apparent quality(color and texture).
\end{abstract}

\section{Introduction}

The Chinese shrimp Fenneropenaeus chinensis, a commercial species widely cultured in northern China coastal areas ${ }^{[1]}$. The yield of Chinese shrimp Fenneropenaeus chinensis reached 48, 167 tons in 2014, increased by $14.87 \%$ than 2013 in the total marine Chinese shrimp Fenneropenaeus chinensis cultured in China ${ }^{[2]}$. After capture, fresh shrimps are extremely perishable associated with microbiological, chemical, and physical changes, frozen storage was an important preservation method to prolong the shrimp shelflife ${ }^{[3]}$. Raw shrimps is susceptible to melanosis during frozen storage, thermal treatment could inactivate PPO associated with good appearance or storage stability ${ }^{[4-5]}$.

Water structure and mobility was well recognized as a relevant parameter that vary during frozen storage in meat ${ }^{[6]}$. Low-field nuclear magnetic resonance (NMR) is a useful technique to investigate the properties of water in shrimps ${ }^{[7]}$. $T_{2}$ transversal relaxation times can be separated into three fractions representing the water distribution and mobility in different compartments, which are characterized by three relaxation times. In muscle foods, it has been proposed that the shortest relaxation component $\mathrm{T}_{2 \mathrm{~b}}$ representing water tightly bind to macromolecules, the major relaxation component $T_{21}$ representing entrapped or immobilized water, and the slower relaxation component $\mathrm{T}_{22}$ is thought to represent free water locating outside the myofibrillar proteinnetwork ${ }^{[8]}$. There was close correlation between the LF-NMR analysis and other physicochemical measurements such as moisture, water-holding capacity, $\mathrm{pH}$ and color ${ }^{[7]}$.

The aim of this present study was to investigate the effects of frozen storage on the textural, color, and water properties of pre-cooked Chinese shrimp Fenneropenaeus chinensis, and to determine the influence of water properties on the quality changes of shrimp samples.

\section{Materials and methods}

\section{Thermal processing and freezing storage for shrimps}

Chinese shrimp Fenneropenaeus chinensis of $18 \mathrm{~g} \pm 2 \mathrm{~g}$ used in this study were purchased from an aquatic market in Jin zhou, China. The fresh shrimp samples were treated in boiling water for 5 min, then the shrimp samples were immediately cooled to room temperature (about $20{ }^{\circ} \mathrm{C}$ ) immediately by running water. Then the thermal processed shrimps were randomly divided into 25 lots, shrimps in each lot were stored in a refrigerator at $-18 \pm 2{ }^{\circ} \mathrm{C}$ for up to 120 days. For each 30 days storage period, 5 lots were thawed in running water for 2 hours and subjected to low-field NMR analysis, 
textural measurements, moisture content, water holding capacity and color measurements. Four measures were taken for each lot.

Nuclear magnetic resonance (NMR) transverse relaxation $\left(\mathbf{T}_{2}\right)$ measurement

NMR relaxation measurements were performed according to Sánchez-Alonso et al. (2012) using a desktop magnetic resonance imaging (MRI) device (NMI20-Analyst, Shanghai Numag Electronic Technology Co., Ltd, Shanghai, China) Portions of $2 \times 0.5 \times 0.5 \mathrm{~cm}$ were cut from the first quarter of thawed shrimp abdomen ${ }^{[6]}$, the samples were placed in test tubes $(1.5 \mathrm{~cm}$ diameter and $15 \mathrm{~cm}$ high). Measurements of the $\mathrm{T}_{2}$ spin-spin relaxation times were taken using the pulse train of the Carr-Purcell-Meiboom-Gill pulse sequence (CPMG).

\section{Hardness and springiness analysis}

Texture analyses (hardness and springiness) of shrimp samples were performed using a TA-XT plus texture analyser (Stable Micro Systems Ltd., Godalming, UK). The first and second intact segment from the anterior of the shrimp head were compressed perpendicularly using a 50-mm flat-ended cylinder probe. Cross-head movement at a constant speed of $1.0 \mathrm{~mm} / \mathrm{s}$, and a trigger point of $5 \mathrm{~g}$. The testing conditions were two consecutive cycles at $30 \%$ compression. Texture variables were calculated as described by Etemadian et al. (2011) ${ }^{[9]}$.

\section{Moisture content}

Shrimp samples were analyzed for moisture content according to the GB 5009.3-2010 method, and the moisture content was calculated as the percentage of weight loss ${ }^{[10]}$.

\section{Water holding capacity (WHC)}

WHC was determined in cooked shrimps (boiled for $5 \mathrm{~min}$ ) muscle by centrifugal method described by Tironi et al. (2010) ${ }^{[11]}$. The WHC was calculated as percentage of retained liquid respect to the initial water content (which was determined by drying at $105{ }^{\circ} \mathrm{C}$ for $24 \mathrm{~h}$ ).

\section{Color determination}

Color parameters on the CIE Lab system $a^{*}$ (redness and greenness), $b^{*}$ (yellowness and blueness), and $\mathrm{L}^{*}$ (brightness) were determined using a WSC-S colorimeter (Shanghai Precidion Instrument Co. Ltd., Shanghai, China) calibrated on a white reference plate before use.

\section{Statistical analysis}

Data were analyzed using analysis of variance (ANOVA) was performed and mean comparisons were obtained by Duncan's multiple range test at $p<0.05$ and Pearson correlation coefficients with the program SPSS 16.0 (SPSS Inc., Chicago, USA). The values were expressed as the means \pm standard deviations.

\section{Results and discussion}

\section{Changes of Moisture content and WHC}

Table 1 shows the mean values for moisture content and WHC versus the frozen storage time. According to these results, longer storage time led to higher shrimp dehydration. The initial moisture content of pre-cooked shrimps was $72.89 \%$, which decreased to $66.67 \%$ at the end of storage time $(\mathrm{p}<0.05)$. The reduction of moisture content could contribute to membrane structure was destroyed and drip loss increased ${ }^{[12]}$ 。

The decrease in WHC of aquatic animal muscle after death was reported by Diaz-Tenorio et al. (2007) for white shrimp (Litopenaeus Vannamei), shrimp exposed to boiling water had a lower WHC than raw shrimps ${ }^{[13]}$, WHC with different storage times were shown in table 1, significant decrease was observed between initial WHC and the final WHC of shrimp samples ( $<<0.05)$. The decrease of WHC is often described as the effect on denaturation of myofibrillar protein in the muscle during cold storage ${ }^{[14]}$. 
Table 1 changes in moisture content and water holding capacity of Chinese shrimp Fenneropenaeus chinensis for different storage time

\begin{tabular}{llllll}
\hline & \multicolumn{5}{l}{ Storage time (d) } \\
\cline { 2 - 6 } & 0 & 30 & 60 & 90 & 120 \\
\hline $\begin{array}{l}\text { Moisture content (\%) } \\
\text { Water holding capacity }\end{array}$ & $72.89 \pm 1.22^{\mathrm{a}}$ & $72.45 \pm 0.88^{\mathrm{a}}$ & $71.30 \pm 2.11^{\mathrm{a}}$ & $68.35 \pm 1.54^{\mathrm{b}}$ & $66.67 \pm 1.05^{\mathrm{b}}$ \\
$(\%)$ & $80.22 \pm 2.65^{\mathrm{a}}$ & $78.36 \pm 2.14^{\mathrm{ab}}$ & $78.11 \pm 1.58^{\mathrm{ab}}$ & $76.85 \pm 2.18^{\mathrm{ab}}$ & $75.32 \pm 2.24^{\mathrm{b}}$ \\
\hline
\end{tabular}
different $(\mathrm{p}<0.05)$

\section{Changes of textural characters}

Textural characters was an important quality parameters for seafood products, hardness and springiness were used to describe the tissue properties in Table 2, the initial hardness of pre-cooked shrimps was $995.6 \mathrm{~g}$, which increased with the increasing of storage time $(\mathrm{p}<0.05)$. Hardness means the force making object deformation, chewing became arduous with the increasing of hardness. In cryopreservation conditions, fish muscle generally becomes tougher, accompanied by a progressive loss of fluid and reduction of water holding capacity, which is defined as the ability of the meat to hold all or part of its own water (immobilized water) during application of external forces-such as cutting, heating, grinding, or pressing ${ }^{[15]}$. In this experiment, the increasing hardness of precooked shrimp samples could be contributed to the diminution of moisture content (Table 1) and progressive loss of fluid. Springiness decreased at the end of storage time of 180 days but small changes during the first 90 days for pre-cooked shrimps stored at $-18{ }^{\circ} \mathrm{C}$, long time storage.

Table 2 Changes in textural properties of Chinese shrimp Fenneropenaeus chinensis for different storage time

\begin{tabular}{llllll}
\hline & \multicolumn{5}{c}{ Storage time (d) } \\
\cline { 2 - 6 } & 0 & 30 & 60 & 90 & 120 \\
\hline Hardness (g) $_{\text {Springiness (mm) }}$ & $995.6 \pm 425 \pm 0.011^{\mathrm{a}}$ & $992.1 \pm 33.8^{\mathrm{c}}$ & $1050.3 \pm 67.5^{\mathrm{c}}$ & $1210.5 \pm 65.1^{\mathrm{b}}$ & $1385.5 \pm 95.6^{\mathrm{a}}$ \\
\hline
\end{tabular}

different $(\mathrm{p}<0.05)$

For each parameter, different letters in the same column indicate significantly

\section{Changes of color}

The color of pre-cooked shrimps is very important regarding the consumer perception of quality, and is a dominant factor in consumer purchasing decisions. Raw shrimps have a natural brown-black appearance, thermal processing in boiling water for 5 min result in the denaturation of protein and color of shrimps turned to be orange red. The effect of frozen storage time on color $\left(\mathrm{L}^{*}\right.$, $\left.a^{*}, \& b^{*}\right)$ of Chinese shrimp Fenneropenaeus chinensis was shown in Table 3 . the initial $L^{*}$ value was 52.35, and at the end of storage, the $\mathrm{L}^{*}$ value increased to $57.60(\mathrm{p}>0.05)$, the result was in accordance with the report by the result of raw shrimps during frozen by Yeilikaya et al. (2010) ${ }^{[16]}$. There is no significantly changes for $a^{*}$ and $b^{*}$ value between the initial and that at the end of the storage time $(p>0.05)$. It was observed from Table 3 that the color preference of pre-cooked Chinese shrimp Fenneropenaeus chinensis was yellow rather than red due to the initial $b^{*}$ value of pre-cooked shrimps was 22.74 , while the initial a* value was 13.63 . The shrimp samples became orange and red for the $\mathrm{a}^{*}$ and $\mathrm{b}^{*}$ value were 15.04 and 24.03 respectively at the end of storage time of $120 \mathrm{~d}$, indicating the frozen storage partially dissociated the protein-carotenoid and produced larger redness and yellowness. 
Table 3 Changes in color of Chinese shrimp Fenneropenaeus chinensis for different storage time

\begin{tabular}{|c|c|c|c|c|}
\hline & \multicolumn{4}{|c|}{ Storage time $(\mathrm{d})$} \\
\hline & 30 & 60 & 90 & 120 \\
\hline $\mathrm{L}^{*}$ & $52.35 \pm 4.21^{\text {a }} 53.49 \pm 2.43^{a}$ & $54.80 \pm 2.04^{a}$ & $55.55 \pm 1.63^{\mathrm{a}}$ & $57.60 \pm 4.93^{\mathrm{a}}$ \\
\hline$a^{*}$ & $13.63 \pm 0.90^{\text {a }} 14.27 \pm 0.95^{a}$ & $14.35 \pm 0.31^{a}$ & $14.85 \pm 2.22^{\mathrm{a}}$ & $15.04 \pm 1.58^{a}$ \\
\hline $\mathrm{b}^{*}$ & $22.74 \pm 1.52^{\text {a }} 24.69 \pm 1.14$ & $25.27 \pm 1.77$ & $25.88 \pm 2.66^{\mathrm{a}}$ & $26.03 \pm 1.35^{\mathrm{a}}$ \\
\hline
\end{tabular}

significantly different $(\mathrm{p}<0.05)$

For each parameter, different letters in the same column indicate

\section{Water contribution and mobility with low field NMR $\mathbf{T}_{\mathbf{2}}$ analysis}

NMR transverse relaxation has proven an excellent tool to quantify the changes in water distribution and mobility during storage or processing and thus help to explain how these changes are linked to meat quality ${ }^{[17]}$. The myowater in the muscle can be classified into three fractions: 1) water tightly bind to macromolecules; 2) entrapped or immobilized water; 3 ) free water ${ }^{[17-18]}$. Three major water populations were observed in the samples (Fig. 1). The shortest relaxation component $\mathrm{T}_{2 \mathrm{~b}}(1-10 \mathrm{~ms})$, accounting for $7.89-9.28 \%$ of the total water (Table 4) in the system and has been considered to be bound water ${ }^{[19]}$. The major relaxation component $\mathrm{T}_{21}$, close to $30 \mathrm{~ms}$ (generally $10-100 \mathrm{~ms}$ ), accounting for $85.67-86.43 \%$ of the total signal (Table 4 ) and was considered to be entrapped or immobilized water bound to the tertiary or quaternary protein structures. Finally the third component $\mathrm{T}_{22}$, with the longest relaxation time, close to $250 \mathrm{~ms}$, accounting for 5.05-5.68\% amount of the total signal and was considered to be free water.

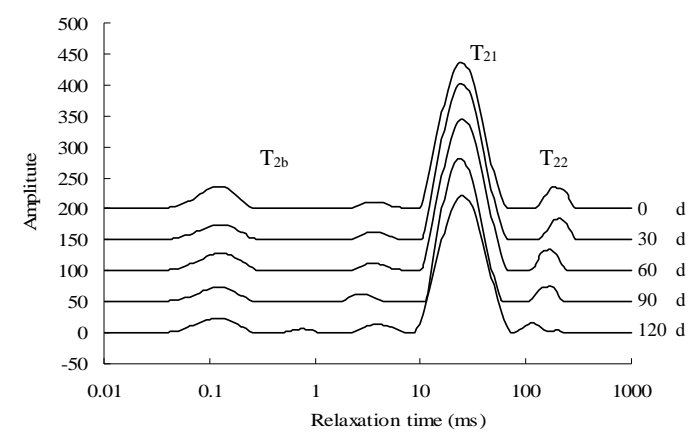

Fig. 1 distribution of lf NMR $\mathrm{T}_{2}$ curves of shrimp samples for different storage time (a),

$\mathrm{T}_{2 \mathrm{~b}}$ is lower than $10 \mathrm{~ms}, \mathrm{~T}_{21}$ is $10-100 \mathrm{~ms}, \mathrm{~T}_{22}$ is greater than $100 \mathrm{~ms}$

The total proportion of $\mathrm{T}_{2 b}$ distributions ( $\left.\mathrm{P}_{2 b}\right)$ increased from $7.89 \%$ (0 days) to $9.28 \%$ (120 days), indicating that more bound water molecules were closely associated with macromolecules. As can be seen from Fig. 1and Table 4, the amplitudes of water populations $\mathrm{P}_{21}$ decreased during the 120 days of frozen storage $(\mathrm{p}>0.05)$. The fractions of $\mathrm{T}_{22}$ distributions $\left(\mathrm{P}_{22}\right)$ decreased from $5.68 \%(0$ days) to $5.05 \%$ (120 days), which suggesting free water were missing during the frozen storage or thawing processing.

Table 4 Corresponding relative populations $\left(\mathrm{P}_{2}\right)$ of shrimp samples obtained from different storage times $(n=4)$

\begin{tabular}{llllll}
\hline & \multicolumn{4}{c}{ Storage time (d) } \\
\cline { 2 - 6 } & 0 & 30 & 60 & 90 & 120 \\
\hline $\mathrm{P}_{2 b}(\%)$ & $7.89 \pm 0.21^{\mathrm{c}}$ & $8.02 \pm 0.18^{\mathrm{bc}}$ & $8.55 \pm 0.55^{\mathrm{abc}}$ & $8.82 \pm 0.63^{\mathrm{ab}}$ & $9.28 \pm 0.54^{\mathrm{a}}$ \\
$\mathrm{P}_{21}(\%)$ & $86.43 \pm 0.58^{\text {a }}$ & $86.36 \pm 3.11^{\mathrm{a}}$ & $86.04 \pm 2.05^{\mathrm{a}}$ & $85.82 \pm 1.35^{\mathrm{a}}$ & $85.67 \pm 1.09^{\mathrm{a}}$ \\
$\mathrm{P}_{22}(\%)$ & $5.68 \pm 0.23^{\mathrm{a}}$ & $5.62 \pm 0.39^{\mathrm{a}}$ & $5.41 \pm 0.66^{\mathrm{a}}$ & $5.36 \pm 0.34^{\mathrm{a}}$ & $5.05 \pm 0.15^{\mathrm{a}}$ \\
\hline \multicolumn{5}{c}{ For each parameter, different letters in the same column indicate }
\end{tabular}
significantly different $(\mathrm{p}<0.05)$

\section{Correlation analysis}

Correlation coefficients among measured variables were listed in Table 5. It was reported that there was changing relationship of WHC and textural characters (Hardness and springiness) $(p<0.05){ }^{[20]}$. In this study, the hardness in the frozen shrimps was strongly correlated with moisture content and $\mathrm{P}_{2 b}$, while springiness was strongly correlated with $\mathrm{P}_{21}, \mathrm{P}_{22}$, moisture content and WHC, indicating that the water distribution within the shrimp muscle had a significant effect on the textural 
characters. $\mathrm{L}^{*}, \mathrm{a}^{*}$ and $\mathrm{b}^{*}$ value were all strongly correlated with $\mathrm{P}_{2 \mathrm{~b}}, \mathrm{a}^{*}$ was furthermore correlated to $\mathrm{P}_{21}$, this result revealed that color changes of frozen pre-cooked shrimps were influenced by the water distribution and mobility.

Table 5 person correlation coefficients between measured variables $(n=28)$

\begin{tabular}{|c|c|c|c|c|c|}
\hline & $\begin{array}{l}\text { Hardness } \\
(\mathrm{g})\end{array}$ & $\begin{array}{l}\text { Springiness } \\
(\mathrm{mm})\end{array}$ & $\mathrm{L}^{*}$ & $a^{*}$ & $b^{*}$ \\
\hline$\overline{P_{2 b}(\%)}$ & $0.911^{* *}$ & -0.274 & $0.837^{* *}$ & $0.783^{* *}$ & $0.878^{* * *}$ \\
\hline $\mathrm{P}_{21}(\%)$ & 0.017 & $0.744^{* *}$ & 0.437 & $0.529^{*}$ & 0.469 \\
\hline $\mathrm{P}_{22}(\%)$ & -0.214 & $0.841^{* *}$ & 0.218 & 0.327 & 0.302 \\
\hline Moisture content (\%) & $-0.705^{* *}$ & $0.919^{* *}$ & -0.182 & -0.026 & -0.144 \\
\hline Water holding capacity (\%) & -0.361 & $0.914^{* *}$ & 0.216 & 0.333 & 0.137 \\
\hline
\end{tabular}

\section{Conclusion}

The study revealed that changes in the textural characters, color and distribution and mobility of water in pre-cooked Chinese shrimp Fenneropenaeus chinensis during frozen storage. In the present study, Frozen storage reduced the moisture content, WHC and springiness, while lightness, red and yellow value, hardness of pre-cooked shrimps increased, low-field NMR $\mathrm{T}_{2}$ result revealed there was water distribution and mobility changes of samples during frozen storage, color and textural characters were all influenced by that changes.

\section{Acknowledgments}

This study was supported by a grant from the National Key Technologies R\&D Program of China during the 12th Five-Year Plan Period (2012BAD29B06).

\section{References}

[1] Y. Y. He, Y. Du, J. Li, P. Liu, Wang, Q. Y., and Z. X. Li, Analysis of DNA methylation in different tissues of Fenneropenaeus chinensis from the wild population and Huanghai No. 1. Acta Oceanologica Sinica, 34 (2015), 175-180.

[2] Fisheries bureau of agriculture ministry, China fishery statistical yearbook. Beijing: China agricultural press, 2015, pp: 28.

[3] S. Sundararajan, A. Prudente, J. D. Bankston, J. M. King, P. Wilson, and S. Sathivel, Evaluation of green tea extract as a glazing material for shrimp frozen by cryogenic freezing. Journal of Food Science, 76 (2011), E511-E518.

[4] K. Manheema, S. Benjakul, K. Kijroongrojana, and W. Visessanguan, The effect of heating conditions on polyphenol oxidase, proteases and melanosis in pre-cooked Pacific white shrimp during refrigerated storage. Food chemisty, 131 (2012), 1370-1375.

[5] X. X. Li, X. Tian, and J. R. Li. Effect of high hydrostatic pressure and thermal processing on the microbiological, biochemical characteristics of white shrimp Litopenaeus vannamei. Food Science and Technology International, 22 (2016) 302-312.

[6] Sánchez-Alonso, I. Martinez, J. Sánchez-Valencia, and M. Careche, Estimation of freezing storage time and quality changes in hake (Merluccius merluccius, L.) by low field NMR. Food Chemistry, 135 (2012) 1626-1634.

[7] C. D. Carneiro, E. T. Marsico, R. D. R. Ribeiro, C. A. Conte, T. S. Alvares, and E. F. O. de Jesus, Studies of the effect of sodium tripolyphosphate on frozen shrimp by physicochemical analytical methods and Low Field Nuclear Magnetic Resonance (LF H-1 NMR). LWT-Food science and technology, 502 (2013), 401-407.

[8] H. C. Bertram, A. H. Karlsson, M. Rasmussen, O. D. Pedersen, S. Donstrup, and H. J. Andersen, Origin of multiexponential $\mathrm{T}_{2}$ relaxation in muscle myowater. Journal of Agricultural and Food Chemistry, 49 (2001), 3092-3100. 
[9] Y. Etemadian, B. Shabanpour, A. R. Sadeghi Mahoonak, A. Shabani, and M. Alami, Cryoprotective effects of polyphosphates on Rutilus frisii kutum fillets during ice storage. Food Chemistry, 129 (2011), 1544-1551.

[10]GB 5009.3-2010, National food safety standard. Determination of moisture in foods. Ministry of Health of the People's Republic of China, Beijing, Chinese Ministry of Health. (2010).

[11]V. Tironi, M. Lamballerie, and A. Le-Bail, Quality changes during the frozen storage of sea bass (Dicentrarchus labrax) muscle after pressure shift freezing and pressure assisted thawing. Innovative Food Science and Emerging Technologies, 11 (2010), 565-573.

[12]S. Duun, and T. Rustad, Quality of superchilled vacuum packed Atlantic salmon (Salmo salar) fillets stored at -1.4 and $-3.6{ }^{\circ} \mathrm{C}$. Food Chemistry, 106 (2008), 122-131.

[13]L. M. Diaz-Tenorio, F. L. Garcia-Carreno, and R. Pacheco-Aguilar, Comparison of freezing and thawing treatments on muscle properties of whiteleg shrimp (Litopenaeus vannamei). Journal of Food Biochemistry, 315 (2007), 563-576.

[14]D. F. Canizales-Rodríguez, V. M. Ocaño-Higuera, E. Marquez-Rios, A. Z. Graciano-Verdugo, J. L. Cárdenas-López, M. S. Yepiz-Gómez, et al., Biochemical, physical, chemical, and microbiological assessment of blue shrimp (litopenaeus stylirostris) stored in ice. Journal of Aquatic Food Product Technology, 24 (2015), 259-269.

[15]V. M. Ocaño-Higuera, Caracterización parcial del comportamiento bioquímico posmortem y desarrollo de productos a partir del callo de almeja catarina (Argopecten ventricosus) y almeja mano de león (Nodipecten subnodosus) de Baja California México, Master thesis, Centro de Investigación en Alimentacióny Desarrollo, Hermosillo, Sonora, Mexico. (1999).

[16]P. Yeilikaya, N. Gokoglu, and O. K. Topuz, Use of Natural Plant Extracts in Batter Coating of Shrimp and Their Effects on The Quality of Shrimp During Frozen Storage. Journal of Food Processing and Preservation, 34 (2010), 127-138.

[17]K. L. Pearce, K. Rosenvold, H. J. Andersen, and D. L. Hopkins, Water distribution and mobility in meat during the conversion of muscle to meat and ageing and the impacts on fresh meat quality attributes-A review. Meat Science, 89 (2011), 111-124.

[18]G. Aursand, L. Gallart-Jornet, U. Erikson, D. E. Axelson, T. Rustad, Water distribution in brine salted cod (Gadus morhua) and Salmon (Salmo salar): A low-field 1H NMR study. Journal of Agricultural and Food Chemistry, 56 (2008), 6252-6260.

[19]E. Huff-Lonergan, and S. M. Lonergan, Mechanisms of water-holding capacity of meat: The role of postmortem biochemical and structural changes. Meat Science, 71 (2005), 194-204.

[20]S. Riebroy, S. Benjakul, W. Visessanguan, and M. Tanaka, Effect of iced storage of bigeye snapper (Priacanthus tayenus) on the chemical composition, properties and acceptability of Som-fug, a fermented Thai fish mince. Food Chemistry, 102 (2007), 270-280. 